\title{
Experimenting with reference referral in a multitype environment
}

\author{
By Kathleen Dunn \\ Head, Reference Department \\ California State Polytechnic \\ University, Pomona
}

\author{
and Myra White \\ Acting Assistant Director \\ Head, Collection Development \\ California State Polytechnic \\ University, Pomona
}

\section{Five libraries that do not belong to a multitype network create an informal one of their own.}

ovina Public Library, Pomona Public Library, Genesha High School Library, Mt. San Antonio College Library, and the University Library at California State Polytechnic University, Pomona (Cal Poly Pomona), are located close to

\section{The large amount of published material, continuing price increases, and inadequate budgets make it impossible for the libraries to be truly self-sufficient.}

each other in southern California. They differ dramatically from each other in the size of their collections, their staffs, and their constituencies. Their resources have been deployed to meet the needs of their primary clienteles. Yet, in reality, none of the libraries can meet all the information needs of their users from their own collections. The large amount of published material, continuing price increases, and inadequate budgets make it impossible for the libraries to be truly self-sufficient.

In the past, information service in the local area was fragmented among different types of libraries whose staffs were not informed enough about local library resources to make appropriate referrals. Reference personnel were well aware that patrons were migrating between the libraries on their own, but they wondered how productive these forays were. Were these patrons fully aware of the services and resources provided by their "own" libraries? What about other library resources in the area that they might need to use, but were unaware of?

We were certain that better informed librarians would provide better service by making appropriate referrals, either back to the patron's home library or forward to other libraries. We wanted to find a way to help reference staff in each library become more aware of the collections and services of the surrounding libraries. Recognizing our shared geography, shared clientele, and interrelated needs, representatives from these libraries came together to develop a project to test the idea that a core group of staff could learn enough about local resources to make meaningful referrals. We put together a grant proposal for a "Pomona-Covina Multitype Network." Participating libraries agreed to reciprocal orientations, training, work exchanges, and the development of a referral form. The project was approved by the California State Library and funded through the Library Services and Construction Act, Title III, for 1988-1989. 
The grant provided us with funds to experiment with a number of activities. Although the activities themselves-orientation, training, internshipswere not new concepts for librarians, the effort to include all three in the grant project was ambitious, given the heavy service demands and modest staffs of the participating libraries. Even though we knew that we had set for ourselves a demanding agenda, we hoped to reap substantial benefits from it. This, in fact, turned out to be the case.

\section{Orientations}

Each participating library prepared an orientation to its clientele, curriculum (if an educational institution), collections, and services. All reference personnel-professional and support staff-participated in the orientations. Since each library is different in size, the orientations varied in length. They also differed in format. Some orientations were conducted as tours with on-the-spot discussion of each area. Others started with formal presentations on clientele, strengths and weaknesses of the collection, services, etc., and ended with a tour. Some libraries included technical services in their orientations, others did not. In all cases, time was permitted for questions. Each library had to present two orientations in order to keep the groups to a reasonable size.

Participants were very positive in their evaluation of the orientations. They appreciated the opportunity to learn about holdings and services in other libraries and to meet colleagues in different types of libraries. Some recommendations they made were to distribute information packets in advance and include library hours and names and telephone numbers of reference personnel, to limit tours to areas that were directly relevant to reference, and to discuss plans for future services.

\section{Internships and training}

In order to ensure a thorough knowledge of the services and collections of participating libraries, we planned to train a representative group of nine librarians to work reciprocally in the reference areas of the five libraries. Training would focus on learning the reference collection in depth. Afterwards, the librarians were to work a prescribed number of hours per week at the reference desks of participating libraries. During the internship phase of the project, the participants would learn firsthand the types of questions asked in each library, the types of patron, etc. We expected this small group of librarians to establish reciprocal, longterm interactions with each other. However, unexpected staff shortages and difficulty in locating temporary librarians to replace permanent staff who would be interning made this level of activity impossible to implement. Based on enthusiastic response to the orientations and the desire of most reference staff to continue their involvement in the project, we decided on an alternative plan that would allow wider participation and a less intensive commitment. The alternative plan focused on continued orientation to reference collections and clientele through both formal and informal activities.

Since Cal Poly Pomona and Pomona Public have the largest staffs and collections, they organized indepth orientations to their reference collections for all grant participants. Emphasis was on the scope of the collection, computerized services such as CDROM, unique sources, and specialized collections such as business reference. Staffing problems prevented other libraries from offering structured sessions on their reference collections.

In the final phase of the grant project, participants spent between two and four hours in the reference departments of each library. Some felt confident enough to assist patrons at libraries other than their own; others just observed or took the opportunity to become more familiar with the collection.

Participants reported many benefits from this phase. They observed that reference service is approached differently in an academic library than it is in a public library: academic reference librarians really do spend more time teaching the use of resources than providing the information needed. In public libraries the emphasis is reversed, and this holds true even when college students use their local public library. Staff discovered reference gems in each library and sometimes added them to their own reference collections. They also found specialized holdings to which patrons could be referred: for example, card files of short stories, plays, songs, and origins of family names; collections of business licenses; expensive business reference sources; and substantial collections of business statistics and national telephone books. Participants saw a wide range of clients using the libraries, which reinforced the impression that all of us serve users other than our primary clientele. Finally, participants appreciated the opportunity to interact on the job with colleagues.

\section{The referral form}

The grant proposal stated that "An appropriate referral form will be developed, tested, and used." Our intention was to provide as much help and information as possible at the first library in order to minimize the effort required at the second one. This form was to be an important outcome of the grant because it would provide referral continuity for both patrons and librarians, and would continue to be used after the grant ended. Developing and 
using a referral form seemed straightforward enough. Indeed, it was not difficult to reach agreement on the content. All members of the steering committee concurred on the importance of including the name of the patron, the referring library, the library referred to, the information needed, the level and amount of material needed, and the sources already checked. The completed form was well designed and easy to use. Reference staff were to fill it out when referring people to another library, and patrons were to present it at the destination library. Completed referral forms would serve us well as an objective, quantifiable result of our success with multitype reference referral. Nevertheless, the form was infrequently used.

We made numerous referrals as a result of our increased knowledge of local collections, but filled out only 28 referral forms. Why were these forms not used? When questioned about it, reference staff gave a number of reasons for their reluctance to use the referral form-e.g., "It is hard to get a patron to wait while the information is collected" and "Filling out a form interrupts the reference process." The chief reason was that staff felt too busy to fill out the forms. They were often hard pressed to record the number of reference transactions, let alone fill out a one-page form for every local referral. Another significant factor was that a number of referrals were made over the telephone.

Despite the general pattern, however, Genesha High School Library had a good experience with the referral form. We discovered that high school students were much more comfortable about going to another library when they had an "official" form in hand.

We conclude from this experience that written referrals require more planning than we were able to provide. A workshop on how to integrate referral forms into normal reference activities might have helped. On the other hand, it may be that while the concept of a referral form is logical, it is not practical. Another grant project might experiment more thoroughly with the content and format of reference referral forms to determine whether or not they can be easily integrated into reference service.

\section{Outcomes}

Many positive benefits emerged from the Pomona-Covina Area Network Grant that will enhance reference referral. Each library shared its periodical holding list. The library at Mt. San Antonio College successfully established dial access to Cal Poly Pomona's online circulation system. Genesha High School Library now has dial access to Pomona Public Library's online catalog. All of us are much more aware of the strengths in surrounding collections and of the expertise of local librarians. These benefits add up to an increased collec- tive ability to help our users find the information that they need. In order to maintain these positive outcomes, we decided to continue sharing periodical lists and to repeat our visits to other libraries in the future.

\section{RBMS Thesauri on sale}

Now you can get five of ACRL's Rare Books and Manuscripts Section's Thesauri for Use in Rare Books \& Special Collections Cataloging for the specially discounted price of $\$ 30$. Binding Terms, Paper Terms, Printing and Publishing Evidence, Provenance Evidence, and Type Evidence are included in this special offer (a $\$ 42$ value if purchased separately). Developed for use in MARC field 755, these thesauri "make the MARC format workable for rare books and manuscript collections" (LRTS). Make sure your RBMS thesauri collection is complete. To order, request ACRL thesauri pre-pack, ISBN \# 0-8389-7513-5, from ALA's Order Services Department, 50 E. Huron St., Chicago, IL 60611; or call toll free (800) 5452433.

\section{New edition of Genre Terms available}

A new edition of Genre Terms: A Thesaurus for Use in Rare Book and Special Collections Cataloguing has just been published by ACRL. The update to the 1983 edition includes 109 new terms for a total of 441 . Developed by members of the ACRL Rare Books \& Manuscripts Section's Bibliographic Standards Committee, the terms are intended for use in MARC field 655 , to designate intellectual genres of textual materials. For example, adding thesaurus terms such as dictionary, cookbooks, or ephemera to the 655 field enables an individual to easily retrieve all materials of these genre. Authorized terms in the new edition are in boldface to facilitate use, and numerous scope notes and cross references have been added and edited. The 90 -page paperback printed on acid-free paper is available for $\$ 19.95$ ( $\$ 16.95$ for ACRL members). Order Genre Terms (ISBN: 0-8389-7516-x) from ALAA Publishing Services, Order Department, 50 E. Huron Street, Chicago, IL 60611; (800) 545-2433. 